\title{
Relationship of scrotal surface temperature measured by infrared thermography to subcutaneous and deep testicular temperature in the ram
}

\author{
G. H. Coulter, P. L. Senger* and D. R. C. Bailey \\ Agriculture Canada Research Station, Lethbridge, Alberta, Canada TIJ 4B1; and *Department of \\ Animal Sciences, Washington State University, Pullman, Washington 99164, U.S.A.
}

\begin{abstract}
Summary. The right testis of 9 anaesthetized rams was removed from the parietal tunica vaginalis and replaced by a surrogate testis (water-filled balloon) through which water of known temperature was circulated. Thermistors were inserted in the surrogate testis, between the scrotal skin and parietal tunica vaginalis on the right side, and deep within the intact left testis. Scrotal surface temperatures over the surrogate and intact testes were measured by infrared thermography. Scrotal surface temperature was correlated $(P<0.01)$ with both subcutaneous $(r=0.95)$ and surrogate $(r=0.91)$ testicular temperature. The temperature differential between scrotal surface $\left(30 \cdot 1 \pm 0 \cdot 1^{\circ} \mathrm{C}\right)$ and deep testicular temperature over the intact side $\left(34.9 \pm 0.09^{\circ} \mathrm{C}\right)$ was $4.8^{\circ} \mathrm{C}$ at an ambient temperature between 24.0 and $26 \cdot 6^{\circ} \mathrm{C}$.

Contact with the scrotal skin is not required to measure scrotal surface temperature by infrared thermography. This, coupled with the close association between scrotal surface temperature and that of underlying structures, will enhance our ability to understand better testicular temperature regulation and scrotal/testicular function.
\end{abstract}

Keywords: ram; scrotum; testes; thermography; temperature

\section{Introduction}

Maintenance of a proper temperature within the testes is essential for normal spermatogenesis (Waites, 1970; Setchell, 1978). For this reason, the ability to monitor scrotal/testicular temperature would be expected to contribute to our understanding of and ability to evaluate scrotal/testicular function. Infrared thermography is a relatively new, non-invasive, radiological technique that provides a pictorial image of the infrared emissions from an object's surface. Analysis of these emissions provides an accurate estimate of surface temperature (AGA Infrared Systems AB, 1983). Presumably, the surface temperature of the scrotum reflects the temperature of underlying structures such as the testes and epididymides. Infrared thermography has been used to study scrotal/testicular function in man (Gold et al., 1977; Layfaye \& Hermabessiere, 1980) and to a limited extent in the bull (Cena \& Clark, 1978; Purohit et al., 1985; Wolfe et al., 1985). However, before accurate interpretations of infrared thermograms can be made, a thorough description of the relationship between scrotal surface temperature, as measured by infrared thermography, and both subcutaneous and deep testicular temperature is required.

The objective of this research was to determine the relationship between scrotal surface temperature in the ram, as measured by infrared thermography, and subcutaneous and deep testicular temperatures. 


\section{Materials and Methods}

Nine mature rams of mixed breeding were used. After intravenous administration of anaesthetic (pentobarbitone sodium, $65 \mathrm{mg} / \mathrm{ml}$; Anthony Products Co, Acadia, CA, U.S.A.), rams were prepared for surgery by thoroughly clipping and scrubbing the anterior scrotum. Before surgery, the control infrared thermograms of the scrotal surface were obtained. The right testis was removed from the parietal tunica vaginalis through a $7-\mathrm{cm}$ incision in the neck of the scrotum. The resulting space was filled with a water-filled balloon (Fig. 1) hereafter referred to as the surrogate testis. The left testis was retained intact without surgical modification. A surrogate testis was used so that deep testicular temperature could be controlled. In this way, the relationship between surface and deep testicular temperatures could be defined critically, because the generation of predictable temperature gradients is difficult to achieve under normal physiological conditions.

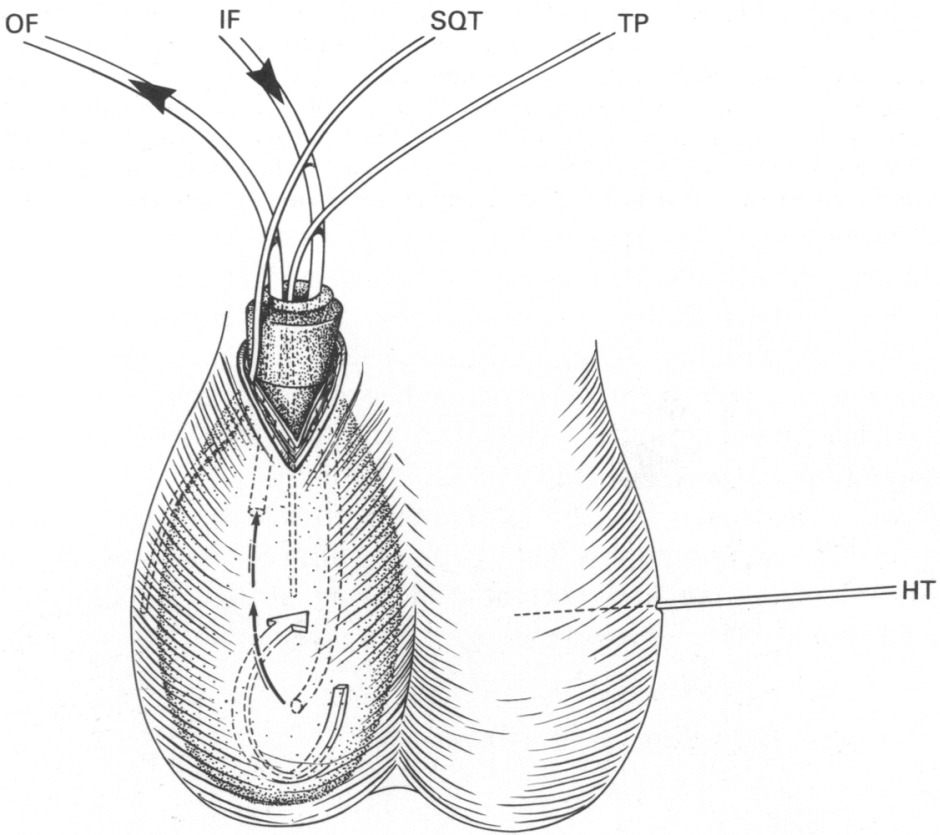

Fig. 1. Anterior view of ram scrotum showing the surrogate testis in place on the ram's right side. IF = inflow tubing; $O F=$ outflow tubing; SQT = subcutaneous thermistor probe; $\mathrm{TP}=$ surrogate thermistor probe; and $\mathrm{HT}=$ hypodermic thermistor probe.

The surrogate testis was an elliptical rubber balloon. The opening of the balloon was fitted with a rubber stopper that contained inflow and outflow tubing $(4.8 \mathrm{~mm}$ i.d.) and a thermistor probe positioned in a central location within the balloon (Fig. 1). Water was pumped through the surrogate testis by inflow tubing using a peristaltic pump (Harvard Apparatus Co., Inc., Millis, MA, U.S.A.). Flow rate of water through the surrogate testis was regulated by a clamp on the outflow tubing (Fig. 2) which permitted the adjustment of internal pressure and size of the surrogate testis to approximate the size of the excised testis. Once the desired surrogate testicular size was achieved, flow rate remained stable throughout the experiment. Flow rate was not quantitated, but appeared to be a minor source of temperature variation once a stable flow rate was attained.

The temperature of water pumped through the surrogate testis was regulated by a thermostatically controlled water bath $\left( \pm 0.04^{\circ} \mathrm{C}\right.$ at $37^{\circ} \mathrm{C}$; range, ambient to $\left.50^{\circ} \mathrm{C}\right)$. Initial temperature of the circulated water was $25^{\circ} \mathrm{C}$. The water was heated to $45^{\circ} \mathrm{C}$ over about $35 \mathrm{~min}$. When the temperature of the water bath reached $45^{\circ} \mathrm{C}$, the intake hose was placed in $25^{\circ} \mathrm{C}$ water to cause a sudden decrease in temperature of the water being circulated. The duration of the complete experiment ranged between 39 and 54 min for different rams, resulting in reduced $n$ values in the later stages of the study. Our goal was to describe the relationship between scrotal surface and deep testicular temperatures. We chose a wide range $\left(25-45^{\circ} \mathrm{C}\right)$ to maximize the chance of fully describing this relationship even though temperatures were at times not physiological. Ambient room temperature ranged between 24.0 and $26.6^{\circ} \mathrm{C}$ throughout the experiment. 
Temperature recordings. Direct temperature recordings were made using thermistor probes attached to a minitabletop polygraph recorder with ICMP amplifying channels (Gilson Medical Electronics, Inc., Middleton, WI, U.S.A.). A stainless-steel probe (Yellow Springs Instrument Co., Inc. (YSI), Yellow Springs, OH, U.S.A.; model 406; accurate to $0.1^{\circ} \mathrm{C}$ within the range of $20-43^{\circ} \mathrm{C}$; time constant $2.5 \mathrm{sec}$ ) was used to measure the temperature within the surrogate testis, while a hypodermic needle probe (YSI model 524 ; accurate to $0.1^{\circ} \mathrm{C}$; time constant $0.1 \mathrm{sec}$ ) was used to monitor deep testicular temperature in the centre of the intact testis. A flexible thermistor probe (YSI model 423; accurate to $0.1{ }^{\circ} \mathrm{C}$ within range $20-43^{\circ} \mathrm{C}$; time constant $1.4 \mathrm{sec}$ ) was inserted between the scrotal skin and the tunica vaginalis on the side containing the surrogate testis (Fig. 1).

Infrared thermography. Scrotal surface temperature data were obtained using a Thermovision 782 system (AGA Infrared Systems AB, Danderyd, Sweden) equipped with a short-wave indium antimonide detector. A thermal range of $20^{\circ} \mathrm{C}$ and a thermal level appropriate for individual rams was used. The infrared thermography scanner, fitted with a $12^{\circ}$ lens, was positioned about $1.5 \mathrm{~m}$ from the scrotal surface (Fig. 2). The scanner lens was nearly parallel to the scrotal surface. Analogue data were recorded on videotape, processed through an analogue to digital converter and analysed using the AGA Digital Image Processing System utilizing Disco 3.0 software (Gesotec Soft- and Hardware GmbH, Darmstadt, F.R.G.). Scrotal surface temperatures were determined by the relative measurement mode, which uses an external reference (black body) with known temperature (range from 24.0 to $26.6^{\circ} \mathrm{C}$ ) and emissivity $(E=1 \cdot 00)$. Temperature of the scrotal surface was based on a mean of 125 pixels in a circular area over the approximate midpoint of the horizontal and vertical axes of the underlying surrogate and intact testis. Time of infrared thermography recordings was synchronized with onset of water infusion into the surrogate testis and with the polygraph recorder. Rectal, surrogate testicular, intact testicular, subcutaneous and scrotal surface temperatures were examined at 3-min intervals.

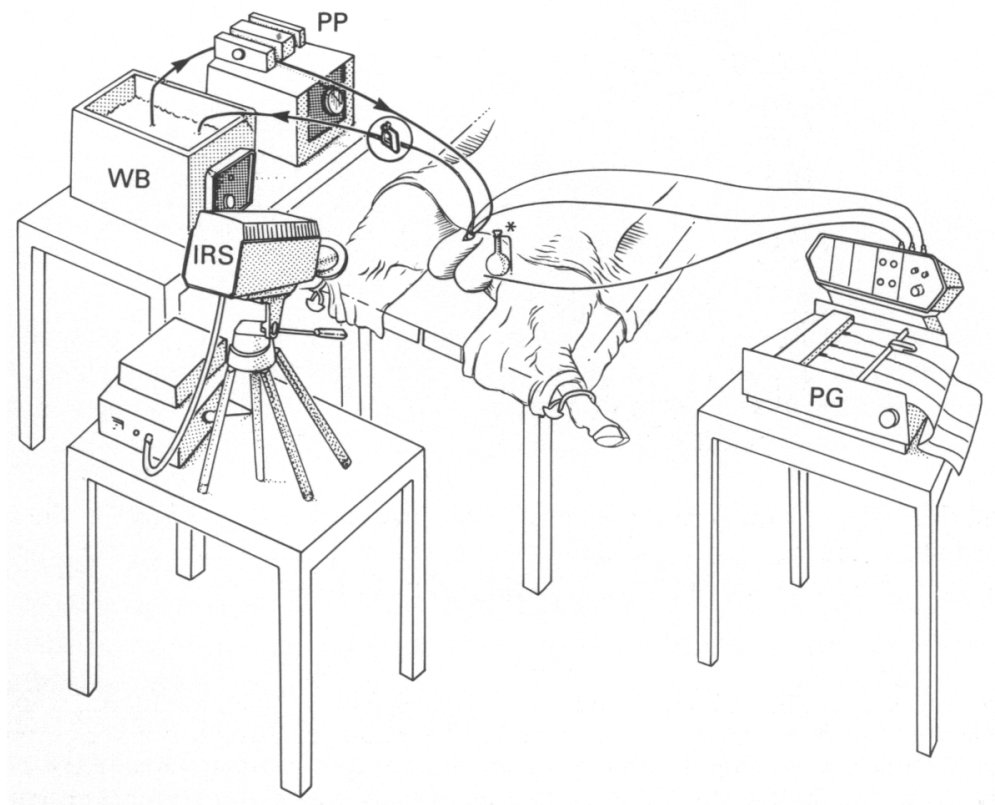

Fig. 2. Experimental apparatus layout used in study. WB = water bath; $P P=$ peristaltic pump; * = external reference (black body); PG = polygraph; IRS = infrared thermography scanner.

Statistical analyses. Preliminary regression analyses were conducted for each of the 9 rams using scrotal surface temperature (determined by infrared thermography) and subcutaneous temperature (between scrotal skin and tunica vaginalis) as the dependent variables and internal surrogate testicular temperature as the independent variable using values up to the maximum temperature. These preliminary analyses indicated that a single model for all rams was inappropriate as regression coefficients for some individual rams were significantly different. Pearson correlation coefficients (Draper \& Smith, 1981) were calculated to describe the association among the variables studied. 


\section{Results}

Mean ( \pm s.e.) rectal temperature for the 9 rams over the course of the experiment remained stable $\left(39.1 \pm 0.03^{\circ} \mathrm{C}\right.$; Fig. 3). Means ranged from $38.6 \pm 0.03$ to $39.6 \pm 0.02^{\circ} \mathrm{C}$ among rams. Deep testicular temperature in the intact testes of rams also remained stable throughout the experiment with some fluctuation in temperature and increased variation in the later stages as the number of rams declined (Fig. 3). There was little apparent influence of surrogate testicular temperature upon the deep testicular temperature of the contralateral intact testis. Mean deep testicular temperature in the intact testes was $34.9 \pm 0.09^{\circ} \mathrm{C}$ and ranged from $33.9 \pm 0.04$ to $35.8 \pm 0.03^{\circ} \mathrm{C}$ among rams.

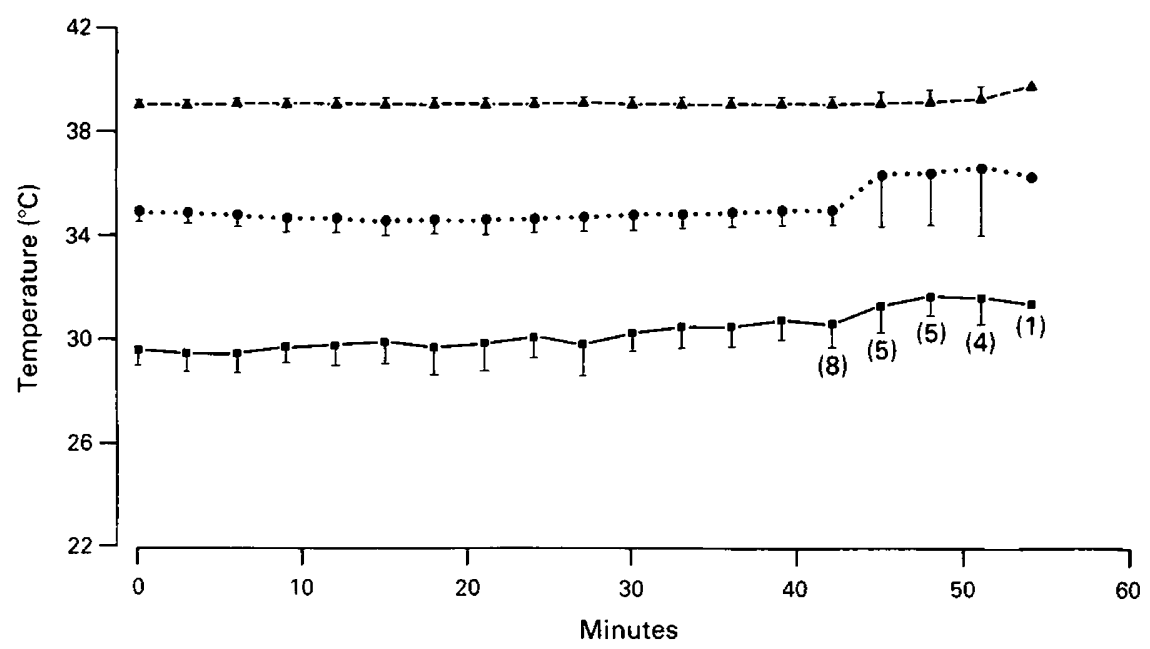

Fig. 3. Changes in mean $( \pm$ s.e.) rectal temperature $(\Delta)$, deep testicular temperature in the intact testis (O), and scrotal surface temperature over the intact testis measured by infrared thermography $(\boldsymbol{D})$ for 9 anaesthetized rams as a function of time. Numbers in parentheses represent the no. of rams if less than 9.

Figure 4 illustrates representative infrared thermograms from one ram showing the scrotum with both testes intact before surgery (control; Fig. 4a) and with the surrogate testis in place (ram's right side) at low (Fig. 4b), intermediate (Fig. 4c), and high (Fig. 4d) internal surrogate testicular temperatures. Scrotal surface temperature over the intact testis, as measured by infrared thermography, remained constant. However, greater variation in scrotal surface temperature was observed throughout the experiment compared with rectal and deep testicular temperatures on the same side (Fig. 3). Mean scrotal surface temperature over the intact testes was $30 \cdot 1 \pm 0 \cdot 1^{\circ} \mathrm{C}$ and ranged from $28.4 \pm 0.2$ to $31.9 \pm 0.1^{\circ} \mathrm{C}$ among rams.

Corresponding mean surrogate testicular, subcutaneous and scrotal surface temperatures of the 9 rams are shown in Fig. 5. At 0, 3, 6, 9 and 12 min of the experiment, surrogate testicular temperature $\left(27 \cdot 1 \pm 0 \cdot 3,27 \cdot 2 \pm 0 \cdot 4,27 \cdot 1 \pm 0 \cdot 2,28 \cdot 2 \pm 0 \cdot 3,29 \cdot 5 \pm 0 \cdot 3^{\circ} \mathrm{C}\right.$, respectively) was similar to subcutaneous temperature $\left(27.8 \pm 0.4,27.5 \pm 0.3,27.5 \pm 0.3,27.8 \pm 0.2^{\circ} \mathrm{C}, 28.9 \pm 0.3^{\circ} \mathrm{C}\right.$, respectively). By $15 \mathrm{~min}$, surrogate testicular temperature $\left(31.0 \pm 0.3^{\circ} \mathrm{C}\right)$ became greater than subcutaneous temperature $\left(29.8 \pm 0.3^{\circ} \mathrm{C}\right)$ and remained greater until the waterbath temperature reached $45^{\circ} \mathrm{C}$ and the intake tubing was placed in $25^{\circ} \mathrm{C}$ water, which caused surrogate testicular temperature to drop rapidly to less than both subcutaneous and scrotal surface temperatures (Fig. 5). Little variation in temperature was noted among rams for surrogate testicular and subcutaneous 

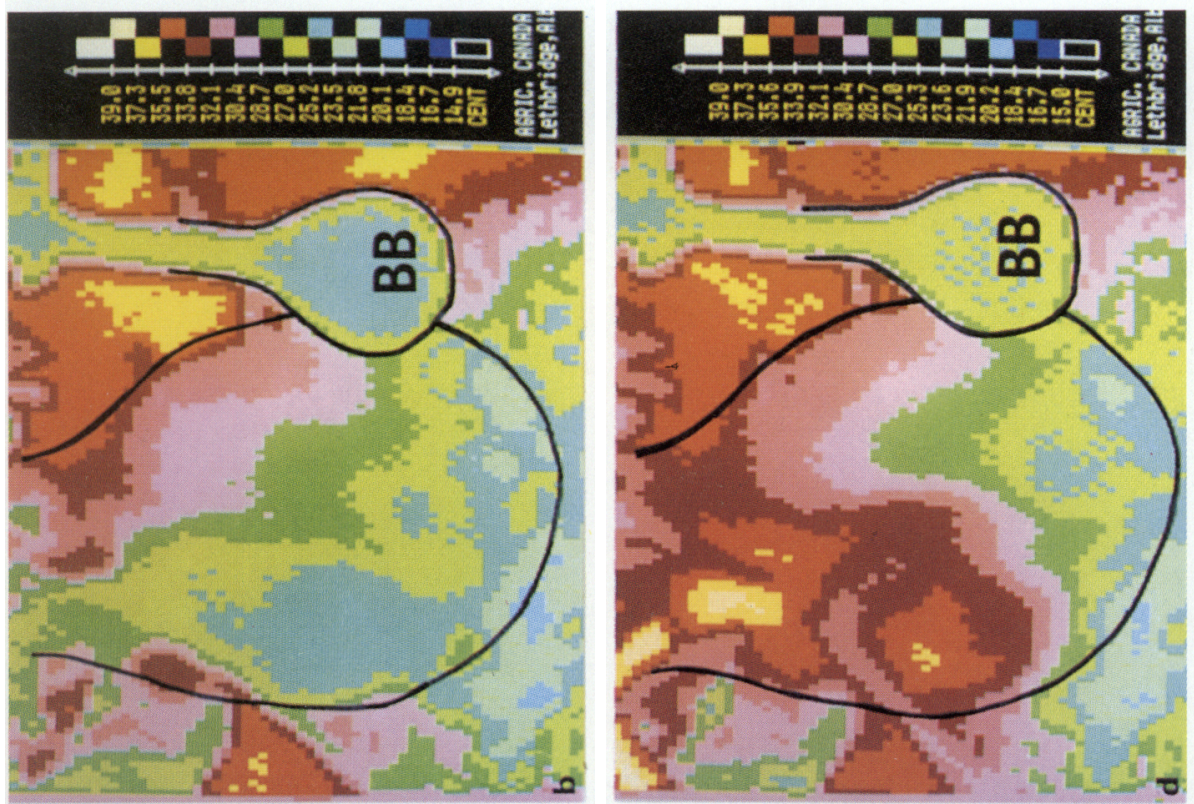

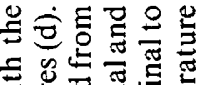
过苋要要

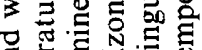

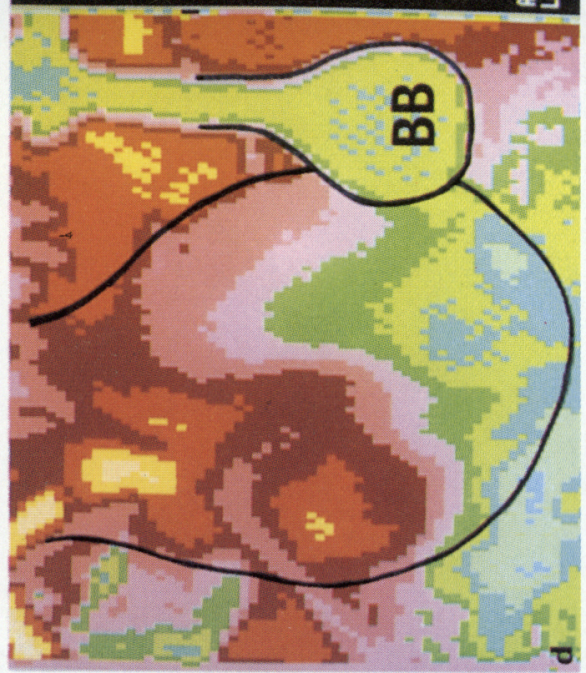
$\Xi$ ¿ กั ङ 군

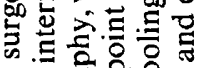
0

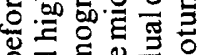
$\triangle$ ह घ 可牙要要 范范吾

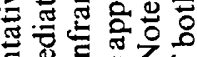

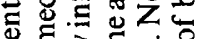
约

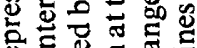

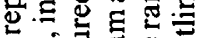

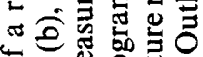

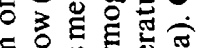

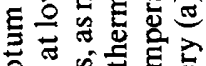

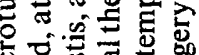

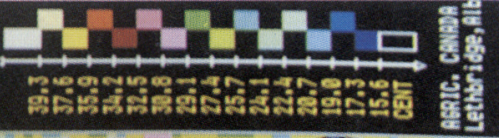

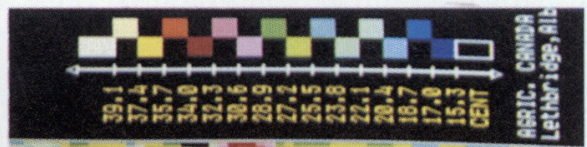
造造洁

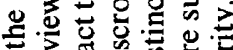

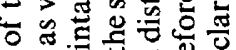

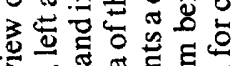

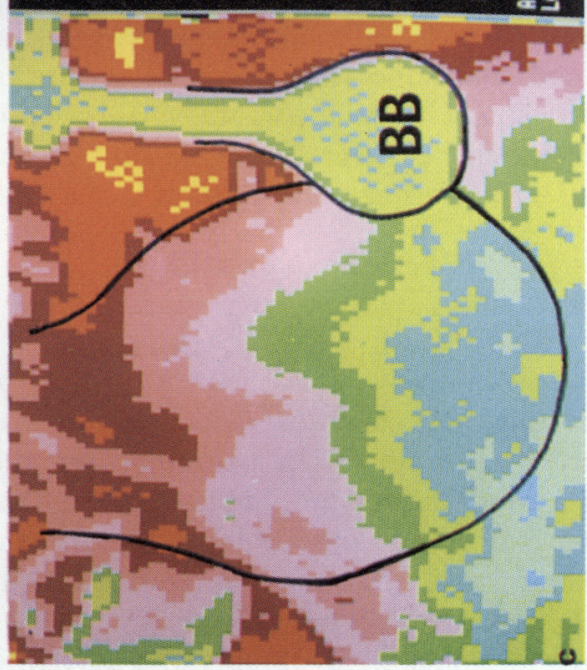

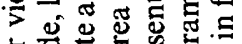

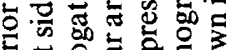

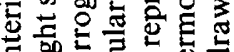
들 के 돌 出 ○芯氙它 है

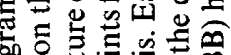
응 원 空㐫过 巳

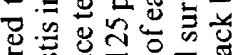

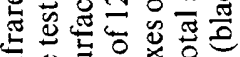

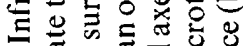

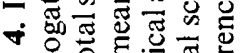

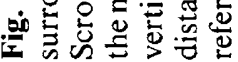


temperatures until the maximum temperature was reached. Variation increased among rams thereafter as the water temperature in the surrogate testis and the number of rams remaining in the experiment were reduced. Scrotal surface temperature (Fig. 5) remained lower than surrogate testicular and subcutaneous temperatures, but was generally parallel to both until after surrogate testicular temperature was reduced sharply, at which point a crossover in temperatures occurred. Variation for scrotal surface temperature was greater than for surrogate testicular or subcutaneous temperature throughout the experiment.

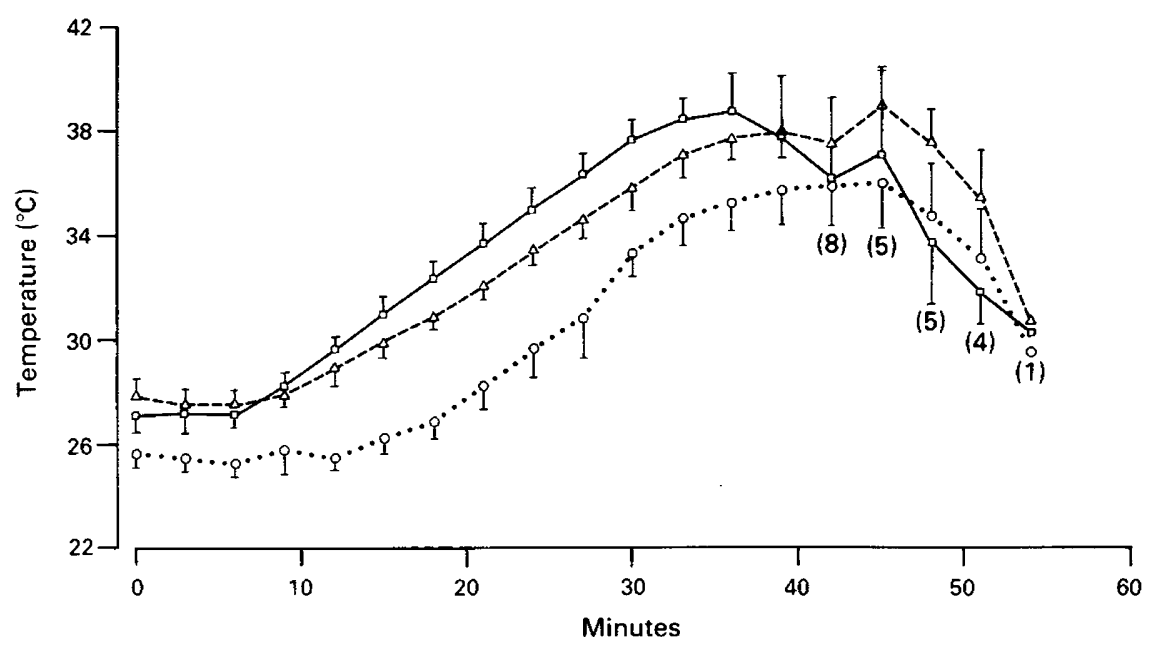

Fig. 5. Changes in mean ( \pm s.e.) surrogate testicular temperature $(\square)$, subcutaneous temperature $(\triangle)$, and scrotal surface temperature $(O)$ measured by infrared thermography for 9 anaesthetized rams as a function of time. Numbers in parentheses represent the no. of rams if less than 9.

Pearson correlation coefficients calculated between surrogate and subcutaneous, surrogate and scrotal surface, and subcutaneous and scrotal surface temperatures were $0.89,0.83$ and 0.95 , respectively $(P<0.01 ; n=9)$. When scrotal surface temperature after a 3-min lag time was used, the correlation coefficients calculated between surrogate testicular and subcutaneous, and surrogate testicular and scrotal surface temperatures increased to 0.92 and 0.91 , respectively $(P<0.01$; $n=9$ ).

\section{Discussion}

The results of this study indicate a close association between scrotal surface temperature measured by infrared thermography and both subcutaneous and deep testicular (surrogate testicular) temperatures in the ram. This relationship has not previously been documented.

Deep testicular temperature $\left(34.9 \pm 0.09^{\circ} \mathrm{C}\right)$ in the intact testis was similar to reported mean testicular tissue temperatures in anaesthetized $\left(34 \cdot 1^{\circ} \mathrm{C}\right.$ ) and conscious $\left(34 \cdot 2^{\circ} \mathrm{C}\right.$ ) rams (Waites \& Moule, 1961). The differential between rectal and deep testicular temperature in this study was $4 \cdot 2^{\circ} \mathrm{C}$. This differential compares favourably with differentials reported previously $\left(3 \cdot 9^{\circ} \mathrm{C}\right.$, Moule \& Knapp, $1950 ; 3.8^{\circ} \mathrm{C}$, Foote et al., $1957 ; 5.6^{\circ} \mathrm{C}$, Waites \& Moule, 1961) in conscious rams. The slight increase in deep testicular temperature in the intact testis accompanied by increased variation in the later stages of the experiment (Fig. 3) may have been a response to the elevated temperature of the adjacent surrogate testis, or possibly due to the smaller number of rams represented at the end of the experiment. 
Scrotal surface temperature over the intact testis as measured by infrared thermography fluctuated slightly more than deep testicular temperature on the same side, but remained parallel, including a slight increase in scrotal surface temperature when deep testicular temperature increased near the end of the experiment. The temperature differentials between the scrotal surface $\left(30.1 \pm 0 \cdot 1^{\circ} \mathrm{C}\right)$ and both rectal and deep testicular sites were 8.9 and $4.8^{\circ} \mathrm{C}$, respectively. The relatively constant scrotal surface temperature over the centre of the intact testis is illustrated in the scrotal thermograms of a representative ram (Fig. 4) when surrogate testicular temperature was low, intermediate and high (Figs $4 \mathrm{~b}, 4 \mathrm{c}, 4 \mathrm{~d}$, respectively). Each colour represents one temperature range. Over the interval of the experiment, the surrogate testis on the ram's right side appeared to have little influence, if any, on the intact left side. However, a more prolonged exposure of a thermally normal testis to an adjacent warmer or cooler testis might be expected to have an effect on the temperature of that testis and subsequent spermatogenesis.

Generally, changes in surrogate testicular temperature were reflected in closely corresponding changes in subcutaneous temperature and scrotal surface temperature measured by infrared thermography (Fig. 5). Two exceptions to this were noted. First, during the initial 12 min of the experiment, subcutaneous temperature was similar to or exceeded surrogate testicular temperature because the surrogate testis was receiving $25^{\circ} \mathrm{C}$ water. As surrogate testicular temperature increased, it exceeded that of the scrotal tissue and a constant temperature differential was established. Secondly, when the circulated water was switched from 45 to $25^{\circ} \mathrm{C}$ a lag time occurred between when the surrogate testicular temperature declined and the subcutaneous and scrotal surface temperatures responded. This lag time in response was expected.

In the past, measurement of scrotal surface temperature was only possible through placing thermistor devices on or within the scrotal skin. This was difficult and potentially inaccurate due to changes in skin contours, alteration of blood flow and/or induction of inflammation at the contact point. Further, temperatures acquired by such methods represented only the point at which the thermistor was located. Infrared thermography technology now facilitates rapid, accurate measurement of temperature over the entire scrotal surface or any portion thereof without contacting the scrotal skin. Infrared thermography therefore appears to have great potential to assist in expanding our understanding of scrotal/testicular function.

We thank W. C. Becker and G. R. Gallagher of W.S.U. for technical assistance and Amy Werner, Biomedical Communications, W.S.U. for preparing Figs 1 and 2.

\section{References}

AGA Infrared Systems, AB (1983) AGA Thermovision 782 Operating Manual. Pub. No. 556556651 Ed. III, AGA Infrared Systems AB, S-18211, Danderyd, Sweden.

Cena, K. \& Clark, J.A. (1978) Veterinary applications of thermography. Acta thermographica 3, 135-141.

Draper, N.R. \& Smith H. (1981) Applied Regression Analysis, 2nd edn. John Wiley \& Sons, Toronto.

Foote, W.C., Pope, A.L., Nichols, R.E. \& Caisda, L.E. (1957) The effects of variations in ambient temperature and humidity on rectal and testis temperature of sheared and unsheared rams. J. Anim. Sci. 16, 144-150.

Gold, R.H., Ehrlich, R.M., Samuels, B., Dowdy, A. \& Young, R.T. (1977) Scrotal thermography. Radiology 122, 129-132.

Lafaye, C. \& Hermabessiere, J. (1980) Thermographic diagnosis of bilateral varicocele. Acta thermographica 5, 155-157.

Moule, G.R. \& Knapp, B. (1950) Observations on intra testicular temperatures of Merino rams. Aust. J. agric. Res. 1, 456-464.

Purohit, R.C., Hudson, R.S., Riddell, M.G., Carson, R.L., Wolfe, D.F. \& Walker, D.F. (1985) Thermography of the bovine scrotum. Am. J. vet. Res. 46, 2388-2392.

Setchell, B.P. (1978) The Mammalian Testis, 1st edn., p. 90. Cornell University Press, Ithaca, New York.

Waites, G.M.H. (1970) Temperature regulation and the testis. In The Testis, vol. 1, p.241. Eds A. D. Johnson, W. R. Gomes, N. L. VanDemark. Academic Press Inc., New York.

Waites, G.M.H. \& Moule, G.R. (1961) Relation of vascular heat exchange to temperature regulation in the testis of the ram. J. Reprod. Fert. 2, 213-224.

Wolfe, D.F., Hudson, R.S., Carson, R.L. \& Purohit, R.C. (1985) Effect of unilateral orchiectomy on semen quality in bulls. J. Am. vet. med. Ass. 186, 129I-1293.

Received 18 December 1987 